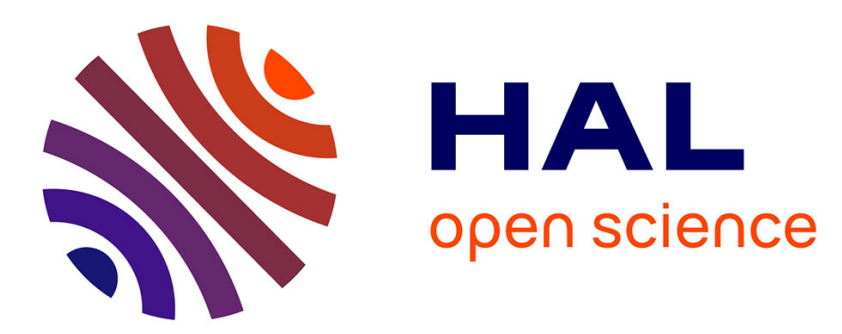

\title{
A 3D finite element model for hyperthermia injury of blood-perfused skin
}

Domoina Ratovoson, Franck Jourdan, Vincent Huon

\section{To cite this version:}

Domoina Ratovoson, Franck Jourdan, Vincent Huon. A 3D finite element model for hyperthermia injury of blood-perfused skin. Computer Methods in Biomechanics and Biomedical Engineering, 2013, pp.Voir DOI. 10.1080/10255842.2013.790963 . hal-00856975

\section{HAL Id: hal-00856975 \\ https://hal.science/hal-00856975}

Submitted on 3 Sep 2014

HAL is a multi-disciplinary open access archive for the deposit and dissemination of scientific research documents, whether they are published or not. The documents may come from teaching and research institutions in France or abroad, or from public or private research centers.
L'archive ouverte pluridisciplinaire HAL, est destinée au dépôt et à la diffusion de documents scientifiques de niveau recherche, publiés ou non, émanant des établissements d'enseignement et de recherche français ou étrangers, des laboratoires publics ou privés. 


\title{
A 3D finite element model for hyperthermia injury of blood-perfused skin
}

\author{
Domoina Ratovoson, Franck Jourdan, Vincent Huon \\ Laboratory of Mechanics and Civil Engineering \\ CNRS, University Montpellier 2
}

France

June 6, 2013

\begin{abstract}
One of the objectives of this study is to propose a numerical model of thermal damage to the skin. This model simulates the propagation of a burn and suggests treatments to prevent it from spreading. In order to achieve this goal, we developed a 3D multi-layer finite elements model of the skin coupled to a model presenting hyperthermic damage. The numerical model of the skin not only takes account of the various layers $\breve{S}$ thermal properties, but also of blood perfusion and veins. The model of damage is based on a law of Arrhenius. We tested two various quick intervention treatments so as to prevent the burn from spreading. The first treatment consists in cooling the burned zone with a flow of cool water at $10^{\circ} \mathrm{C}$, while the second solution simulates the apposition of ice on the burn. The results show that according to the severity of the burn the second treatment seems to be the most appropriate. Moreover, our model opens interesting prospects in the analysis of hyperthermic damage.
\end{abstract}

Thermal damage; Skin; Finite element; Burn limitation

\section{Introduction}

Hyperthermia injury occurs after temperature elevation in tissues over a threshold value for a period of time. The first relationship between temperature, exposure duration and some specific degree of thermal injury is due to (Moritz and Henriques, 1947a), (Moritz and Henriques, 1947b). The damage produced was modeled by an Arrhenius equation type where a rate of chemical process is supposed to depend on the exposure duration for a given temperature. Twelve years later (Stoll and Greene, 1959) proposed two kinetic equations :

${ }^{*}$ Corresponding author: Address: Laboratoire de Mécanique et Génie Civil, CC48, Université de Montpellier 2, Place Eugène Bataillon, 34095 Montpellier, France; phone: 33467149633; fax: 33467143923; email:jourdan@lmgc.univ-montp2.fr 
one for low temperatures and the other for high temperatures. The parameters of the damage law were different from those chosen by Henriques and Moritz. Since these publications, the scientific community worked to determine the parameters of the damage law. In his paper (Wright, 2003), N. T. Wright presented a large review of Arrhenius's parameters, found in literature and underlined a relationship between them.

In parallel, the scientific community worked to build predictive numerical models of hyperthermia injury. In 1983, Diller and Hayes (Diller and Hayes, 1983) presented a finite element model of burn injuries in blood-perfused skin. Since this date, many models and studies were carried out on the subject (Jiang et al., 2002), (Ng and Chua, 2002), (Chang and Nguyen, 2004), (Sramek et al., 2009), (Fuentes et al., 2010). Different sources of burns (laser, radio frequency, fluid, ...) were simulated on different tissues (skin, retinal, liver, ...). Among these publications, recent numerical approaches (Fuentes et al., 2010), (Museux et al., 2012) gave good predictive results on animal tissues.

The numerical model of thermal damage developed here aims at simulating the propagation of a skin burn and at proposing treatments to limit its expansion. Similar studies were presented by (Ng and Chua, 2002) and by (Becker and Kuznetsov, 2007). Here, we propose a 3D multi-layer finite elements model of the skin coupled to a model of hyperthermic damage. The numerical model of the skin not only takes account of the various layers thermal properties, but also of blood perfusion and veins. It was validated using infrared measurements on human subjects in (Ratovoson et al., 2011). The model of damage is based on a law of Arrhenius. We propose to simulate two treatments of quick intervention in order to prevent the burn from spreading. The first treatment consists in cooling the burned zone thanks to a flow of cool water, while the second method simulates the apposition of ice on the burn.

\section{Modeling}

The model proposed in this paper, is a three-dimensional multi-layer in which the veins are considered as fluid continuous media. As reported in (Becker and Kuznetsov, 2007) the skin is composed of 4 layers, which are: the stratum corneum, the epidermis, the dermis and the hypodermis. They highlighted the importance to consider composite structures for skin modeling. As in papers (Jiang et al., 2002), (Museux et al., 2012), (Becker and Kuznetsov, 2007), (Becker and Kuznetsov, 2007) the epidermis, the dermis and the hypodermis are solid continuous media in which the heat transfer is controlled by a Pennes equation type. To complement the numerical model, the thermal damage is controled by an Arrhenius law.

\subsection{Heat transfer in a fluid continuous medium}

To model blood, the equations governing heat transfer in a fluid continuous medium are presented. The velocity vector of a particle $P$ of position $(x, y, z)$ at time $t$ is noted $\underline{U}=$ $\left(u_{x}, u_{y}, u_{z}\right)$. The strain rate tensor is defined by

$$
\underline{\underline{\varepsilon}}=\frac{1}{2}\left(\underline{\underline{\nabla u}}+\underline{\underline{\nabla u^{t}}}\right)
$$

The temperature is noted as $T$. Heat transfer in a homogeneous, incompressible and 
viscous fluid is controlled by the following partial derivative equation

$$
\rho C \frac{\partial T}{\partial t}-k \Delta T+\rho C \underline{U} \cdot \underline{\nabla} T=\mu\left(2 \underline{\underline{\varepsilon}}-\frac{2}{3} \underline{\nabla} \cdot \underline{u I}\right): \underline{\underline{\nabla u}}+r
$$

where $\rho$ is the specific mass $\left(\mathrm{kg} \cdot \mathrm{m}^{-3}\right)$,

$C$ is the specific heat $\left(\mathrm{J} \cdot \mathrm{kg}^{-1} \cdot{ }^{\circ} \mathrm{C}^{-1}\right)$,

$k$ is the thermal conductivity $\left(\mathrm{W} \cdot \mathrm{m}^{-1} \cdot{ }^{\circ} \mathrm{C}^{-1}\right)$,

$\mu$ is the viscosity (Pa.s),

$r$ is the heat source $\left(\mathrm{W} \cdot \mathrm{m}^{-3}\right)$. (neglected in our study)

\subsection{Pennes equation}

To model the biological tissues constituting the skin, the Pennes model was chosen. The first biothermal equation was developed by Pennes in 1948 (Pennes, 1948). There are two mechanisms at stake when we deal with heat transfer in living bodies: blood flow and metabolism. Before undertaking any study, it is necessary to determine which scale to consider in studying heat transfers. Indeed the size of the blood system may vary. The Pennes model proves to be the most appropriate and effective, with a scale ranging from a millimeter to several centimeters Weinbaum and Jiji (1985). Pennes made the assumption that in a given volume of study, heat transfer between the blood and the tissue is proportional to the temperature difference between the arterial blood temperature $T_{a}$ (entering the volume of study) and the (outgoing) venous blood temperature $T_{v}$. The proportionality factor $w$ is called rate of perfusion. The metabolism is also included in the biothermal equation as a distribution of energy source :

$$
Q_{m e t}=Q_{m e t}^{o} Q_{10}^{\frac{T_{o}-T}{10}}
$$

where $Q_{m e t}^{o}$ is the basal metabolism at $37^{\circ} \mathrm{C}, Q_{10}$ is the coefficient of temperature dependence ranging between 2 and $3 \mathrm{~W} \cdot \mathrm{m}^{-3}$ and $T_{o}$ is chosen at $37^{\circ} \mathrm{C}$.

The general biothermal equation obtained with the balance of energy for a volume of tissue taking account of the blood perfusion and the metabolism is given by :

$$
\rho C \frac{\partial T}{\partial t}-\underline{\nabla} k_{t} \cdot \underline{\nabla} T=w \rho_{b} C_{b}\left(T_{a}-T_{v}\right)+Q_{m e t}
$$

where $\rho C \frac{\partial T}{\partial t}$ is the stored energy $\left(\mathrm{W} . \mathrm{m}^{-3}\right), \underline{\nabla} k_{t} \cdot \underline{\nabla} T$ is the heat conduction $\left(\mathrm{W} . \mathrm{m}^{-3}\right), k_{t}$ is the thermal conductivity of the tissue, $w(\rho C)_{b}\left(T_{a}-T_{v}\right)$ is the heat transport generated by perfusion $\left(\mathrm{W} \cdot \mathrm{m}^{-3}\right)$. The index $b$ is reserved for blood coefficient of materials. $Q_{m e t}$ is the metabolic internal power therefore generated $\left(\mathrm{W} . \mathrm{m}^{-3}\right)$.

For years, the Pennes model was criticized by some and defended by others. Despite these controversies and criticisms, most mathematical analyses carried out in biothermal transfers continue to be based on this equation (Klinger, 1974), (Weinbaum et al., 1984), (Jiang et al., 2002), (Ng and Chua, 2002), (Sramek et al., 2009), (Museux et al., 2012). 


\subsection{Assumptions}

To solve the problem, the following assumptions were made:

- Only two layers (dermis and hypodermis) were taken into account. The stratum corneum and the epidermis were neglected because of their lack of thickness.

- $k_{t}$ was chosen constant, thus $\underline{\nabla} k_{t} \cdot \underline{\nabla} T=k_{t} \Delta T$.

$-T_{v}=T$

- The generation of metabolic internal power $Q_{m e t}$ was taken as constant in the dermis and the hypodermis.

- A model of $10 \times 4 \mathrm{~cm}^{2}$ of surface and $4 \mathrm{~mm}$ of thickness was used (see figure 1).

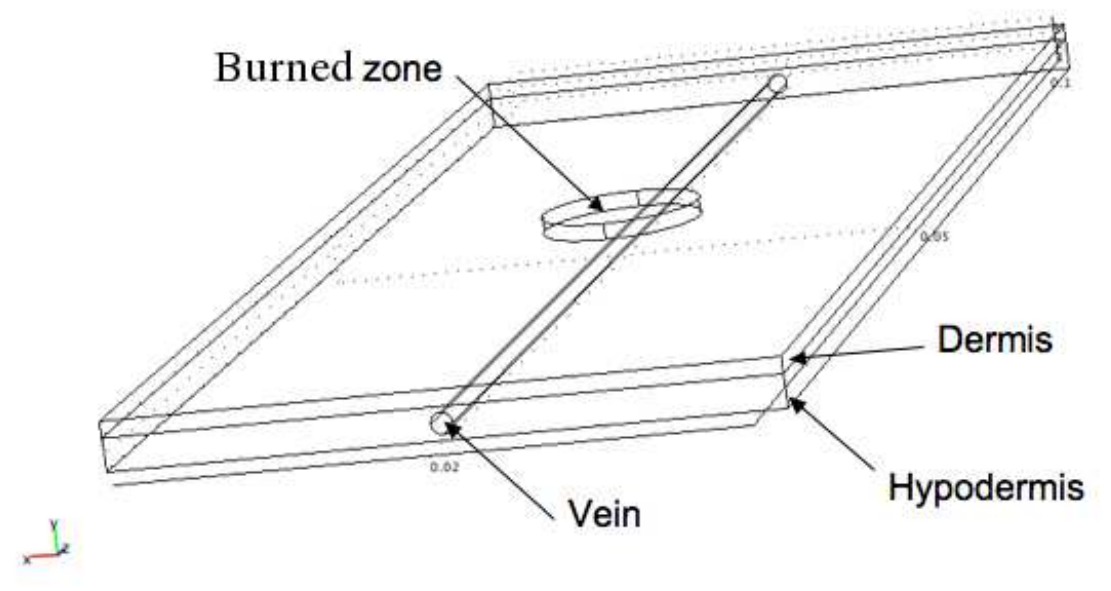

Figure 1: 3D model of skin

- The vein is placed between the dermis and the hypodermis. Blood circulation was created by using a material having transport velocity properties: equation [1].

- The position of the vein is determined by the coordinates of its axisŠs center $x_{c}$ and $y_{c}$.

- The blood is assumed to be an incompressible and viscous fluid and the flow is assumed to be stationary. The velocity of the blood is then a parabolic function of direction $\vec{z}$ :

$$
u_{z}(x, y, z)=-\frac{U_{\max }}{R^{2}}\left[\left(x-x_{c}\right)^{2}+\left(y-y_{c}\right)^{2}\right]+U_{\max }
$$

where $U_{\max }$ is the maximum velocity in the section of the vein and $R$ is the radius of the 
vein. According to (Ratovoson et al., 2011), $U_{\max }$ was taken at a value equals to $2.3 \mathrm{~cm} / \mathrm{s}$ and vein depth was $1 \mathrm{~mm}$.

- The properties of materials are coming from (Gowrishankar et al., 2004) and collected in table 1.

\begin{tabular}{|c|c|c|c|c|c|c|}
\hline $\begin{array}{c}\text { Sub-domain } \\
\text { number }\end{array}$ & Layer & $\begin{array}{c}\text { Thickness } \\
(\mathrm{m})\end{array}$ & 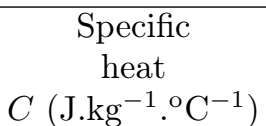 & $\begin{array}{c}\text { Thermal } \\
\text { conductivity } \\
k\left(\mathrm{~W} \cdot \mathrm{m}^{-1} \cdot{ }^{\circ} \mathrm{C}^{-1}\right)\end{array}$ & $\begin{array}{c}\text { Specific } \\
\text { mass } \\
\rho\left(\mathrm{kg} \cdot \mathrm{m}^{-3}\right)\end{array}$ & $\begin{array}{c}\text { Rate } \\
\text { of perfusion } \\
w\left(\mathrm{~s}^{-1}\right)\end{array}$ \\
\hline 0 & Epidermis & $0.0810^{-3}$ & 3590 & 0.24 & 1200 & 0 \\
\hline 1 & Dermis & 0.001 & 3300 & 0.45 & 1200 & 0.00125 \\
\hline 2 & Blood & $0.0013^{*}$ & 3770 & 0.45 & 1060 & 0 \\
\hline 3 & Hypodermis & 0.003 & 2500 & 0.19 & 1000 & 0.00125 \\
\hline
\end{tabular}

Table 1: Material properties: $0.0013^{*}$ is the diameter of the veins and can vary from 1 to 3 $\mathrm{mm}$

All these assumptions and parameter values have been validated for a forearm skin using infrared and echo Doppler measurements (see our previous paper (Ratovoson et al., 2011) ).

\subsection{Damage model}

The rate of thermal damage in tissues is used to evaluate and quantify the damage undergone by the skin following a burn. One can evaluate the rate of thermal damage by:

$$
\frac{d \Omega}{d t}=A e^{-\frac{E_{a}}{R T(t)}}
$$

where $\Omega$ stands for the thermal damage and is uniteless, $A$ is the frequency factor (expressed in $\mathrm{s}^{-1}$ ). It can take values from $4.1110^{53}$ to $9.3910^{104}\left[\mathrm{~s}^{-1}\right]$ (Wright, 2003) for epidermis tissues. $E_{a}$ is the activation energy for skin and is varying from $3.3910^{8}$ to $6.6510^{8}\left[\mathrm{~J}^{\mathrm{kmol}} \mathrm{kmo}^{-1}\right.$ ]. $R=8.315 \mathrm{~J} . \mathrm{mol}^{-1} \cdot \mathrm{K}^{-1}$, is the universal gas constant.

\subsection{Initial and boundary conditions}

- Permanent boundary conditions : A temperature $T_{a}$ was imposed on the lower part of the hypodermis, on the lateral walls and at the entrance of the vein (scheme (a) of figure 2). On the front and back surfaces heat flux was null (scheme (b) of figure 2). The upper part of the dermis (except the disc of radius : $1 \mathrm{~cm}$ ) was subject to heat transfer by convection (scheme (c) of figure 2). Convection was modeled by Newton's law of cooling :

$$
k \frac{\partial T}{\partial n}=h\left(T-T_{e}\right)
$$

where $n$ is the normal vector at the surface, $h$ is the coefficient of convection and $T_{e}$ is the temperature of air. We chose $h=7 \mathrm{~W} \cdot \mathrm{m}^{-2} \cdot{ }^{\circ} \mathrm{C}^{-1}$ (see (Xu et al., 2008)) and $T_{e}=20^{\circ} \mathrm{C}$.

The connection between the layers was ensured by the continuity of the heat flow. 

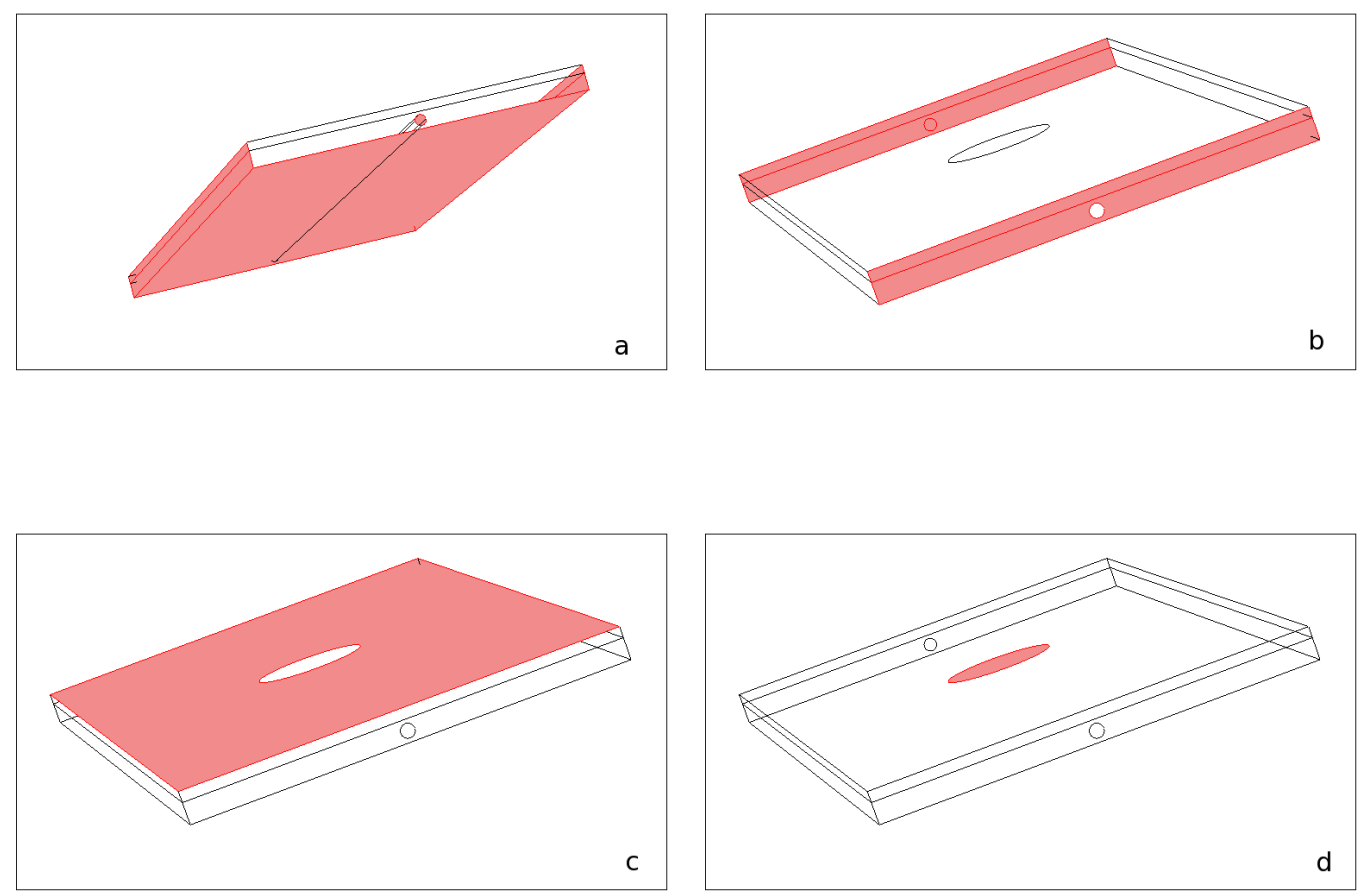

Figure 2: Boundary zones: (a) $T=T_{a}$, (b) null heat flux, (c) convection with air, (d) conditions depend on the treatment

- In order to ensure a stationary distribution of temperature in tissues, before the burning process, an initialization step of sufficient duration (200 seconds) was included. Then, simulations of burn and health care treatments were carried out in three steps. On the disc of $1 \mathrm{~cm}$ of radius on the dermis' upper part (scheme (d) of figure 2) three different thermal conditions were applied.

- Step 1 (Burning step): On the disc, the temperature was increased to $T_{\max }$ in order to emulate the burning process.

- Step 2 (Reaction time): This step corresponds to the reaction time vis-a-vis the burn. It was limited to 5 seconds. The same boundary conditions were imposed as in step 1 , but the burning process was replaced by convection with air. Thus, all the upper part of the dermis was subject to convection.

- Step 3 (Health care): Two approaches were proposed to reduce the damage caused by the burn in order to limit its spread:

+ Treatment by water: The burned zone was under a flow of water during $35 \mathrm{~s}$. The convection was induced by fluid movements and modeled by a forced convection. The convection coefficient can take values between 100 and $15,000\left[\mathrm{~W} \cdot \mathrm{m}^{-2} \cdot \mathrm{K}^{-1}\right]$. In our computations the convection coefficient $h_{\text {water }}$ was chosen at a value equal to 500 
$\left[\mathrm{W} \cdot \mathrm{m}^{-2} \cdot \mathrm{K}^{-1}\right]$. It corresponds to a convection due to a flow coming from ordinary tap water of diameter $15 \mathrm{~mm}$ and assuming a flux of $45 \mathrm{l} / \mathrm{min}$ (ejection velocity of about $4 \mathrm{~m} / \mathrm{s}$ ). For a horizontal laminar plane flow, we used the following expression for the Nusselt number:

$$
N_{u}=0.66(\operatorname{Pr})^{1 / 3}(R e)^{1 / 2}
$$

where $\operatorname{Pr}$ is the Prandtl number and Re the Reynolds number. The Nusselt number is linked with $h_{\text {water }}$ by the following relationship:

$$
h_{\text {water }}=k_{f} N u / L
$$

where $k_{f}$ is the fluid thermal conductivity $(0.6 \mathrm{~W} / \mathrm{m} . \mathrm{K})$ and $L$ is the length of the model $(10 \mathrm{~cm})$. For a water with a specific heat of $4180 \mathrm{~J} / \mathrm{kg} . \mathrm{K}$, a mass density of $1000 \mathrm{~kg} / \mathrm{m} 3$ and a dynamic viscosity of 10-3 Pa.s, the Nusselt number is equal to 83. The water temperature was chosen at $10^{\circ} \mathrm{C}$, which is an average value coming from ordinary tap water.

+ Treatment by ice: we proposed to simulate an ice apposition on the burned zone. The temperature was maintained equal to $T_{\min }=1^{\circ} \mathrm{C}$ on the burned zone during $35 \mathrm{~s}$.

These two treatments were compared with a

+ Treatment by air: Like in step 2 external surface is under air convection during 35 s. It means that no treatment is applied to cure the burn.

Obviously, the modeling we suggested to simulate the action of the burner and the ice (maintaining a constant temperature $T_{\max }$ or $T_{\min }$ ) is quite oversimple and would require to be refined.

\section{Numerical simulations}

Concerning the numerical resolution of heat equations (1) and (3), the finite element method was chosen and an implicit time integration scheme was adopted. The mesh contains 13.593 quadratic tetrahedral elements (see figure 3).

This algorithm was programmed using COMSOL and MATLAB softwares. Calculations were carried out with a time step $\Delta t=t_{i+1}-t_{i}=0.25 \mathrm{~s}$. The generations of metabolic internal power in the dermis and the hypodermis were fixed at $368 \mathrm{~W} \cdot \mathrm{m}^{-3}$ (see (Roetzel and Xuan, 1998)). The numerical model was validated and was able to estimate blood velocities (see (Ratovoson et al., 2011)). The thermal response of the skin depends on its thickness. During the phase of validation of the model, we modified the thickness of the layer of dermis in varying the depth of the vein, because the vein was supposed to be the separation between dermis and hypodermis. We varied the radius of the vein too. The depth of the vein was locally measured with echo Doppler and an average of $1 \mathrm{~mm}$ was chosen to best-fit thermal measured responses.

New developments concern the coupling with the thermal damage. The rates of thermal damage integration were computed with an Euler implicit scheme as follows

$$
\Omega\left(t_{i+1}\right)=\Omega\left(t_{i}\right)+\Delta t A e^{-\frac{E_{a}}{R T\left(t_{i+1}\right)}}
$$




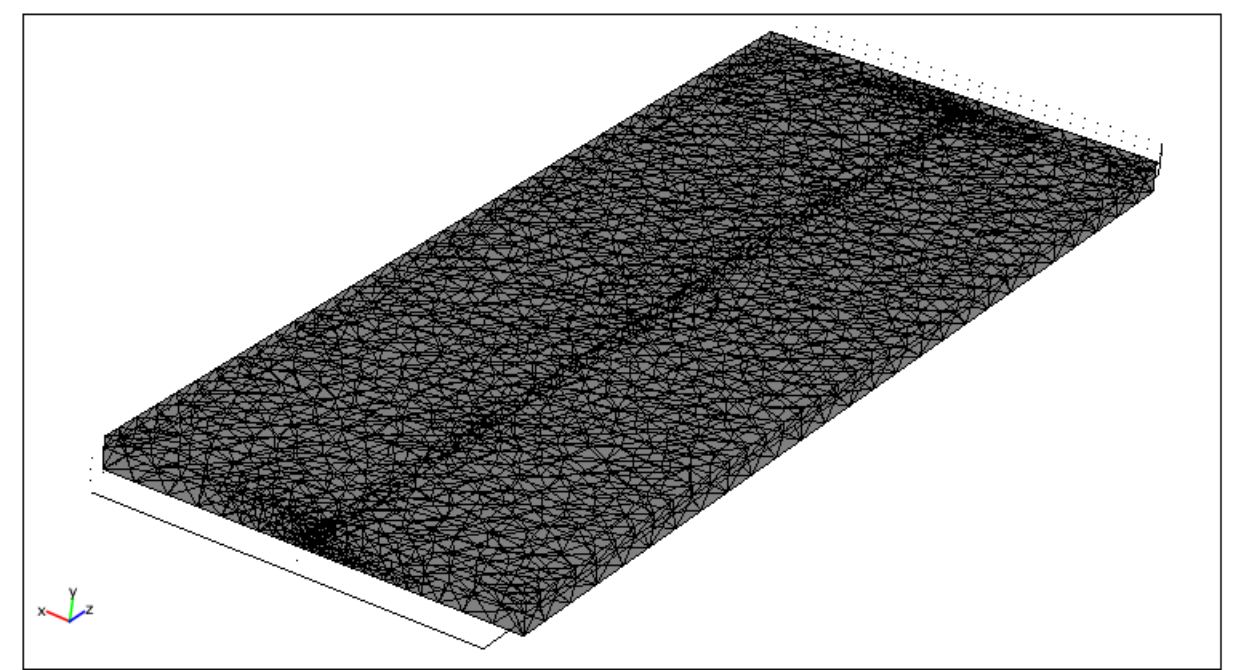

Figure 3: Finite element mesh : 13.593 quadratic thetrahedral elements

Temperatures at time $t_{i+1}$ were given by the previous thermomechanical calculations. The coupling only was considered from the thermomechanical model to the thermal damage model. The influence of thermal damage on thermomechanical properties was not taken into account. We are aware that such simplified assumption is wrong, but currently we are not able to model this coupling.

Two cutting planes of symmetry was defined to show numerical results for thermal damage: the longitudinal plane A-A and the transversal plane B-B (see figure 4).

\subsection{Hyperthermia injury evaluation : no health care}

Following results were obtained after burning simulations. For all computations, the activation energy of the skin was $E_{a}=6.2710^{8}\left[\mathrm{~J}_{\mathrm{kmol}} \mathrm{km}^{-1}\right]$. Figure 5 represents the damage in the longitudinal cutting plane A-A at the end of the simulation. These results were carried out with a factor of frequency $A=3.110^{90} \mathrm{~s}^{-1}$. Calculations simulated a treatment by air. The result on the left was obtained after applying a burning temperature $T_{\max }=400^{\circ} \mathrm{C}$ during an exposure duration $t_{\Omega}=10 \mathrm{~s}$. The result on the right was found after applying a burning temperature $T_{\max }=100^{\circ} \mathrm{C}$ during an exposure duration $t_{\Omega}=5 \mathrm{~s}$. These results are valid for the two most extreme cases of burning. It is noted that for a severe burn, the damage reached the vein and was transported with blood flow.

Left image of figure 6 represents the damage on the upper surface of the model at the end of the simulation, for the severe burn. A light transport of the damage caused by the vein, can be seen at the bottom of the disc. Right image of figure 6 represents the damage 


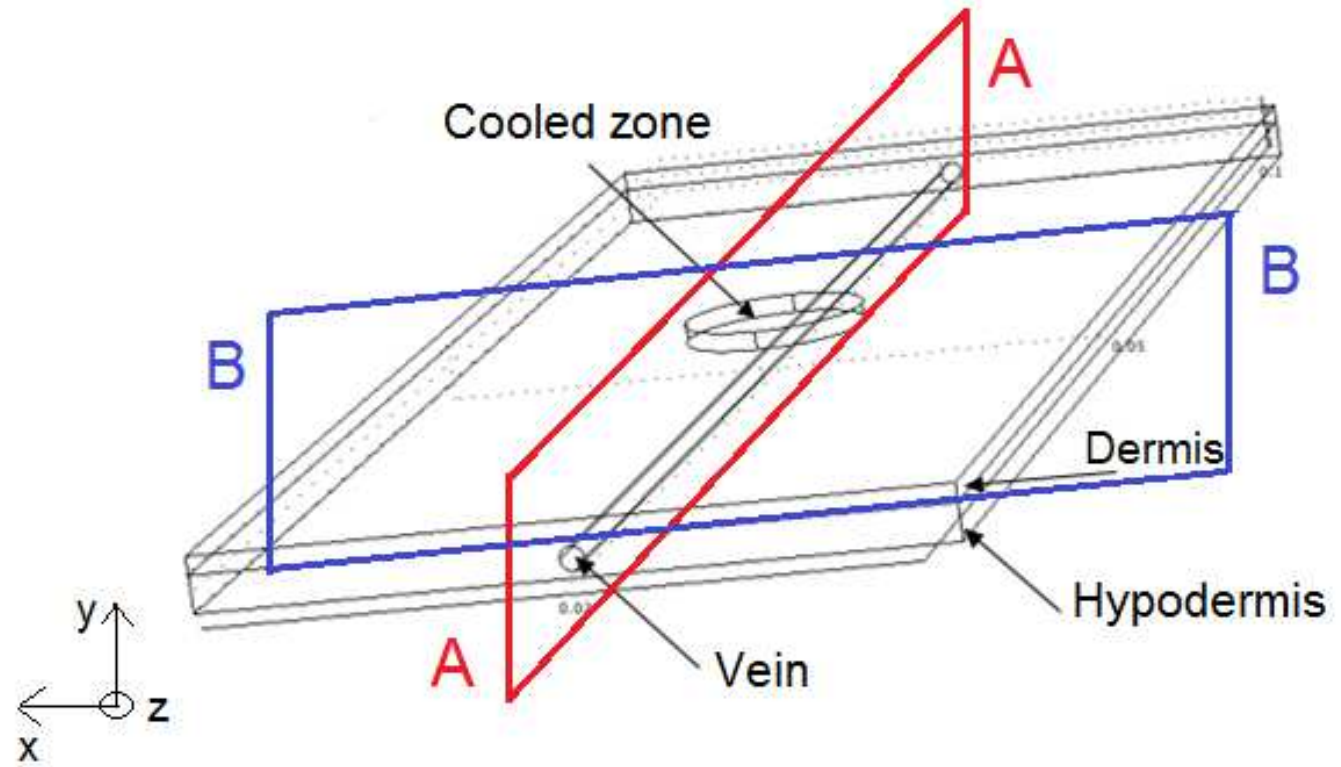

Figure 4: Cutting planes : longitudinal A-A and transversal B-B
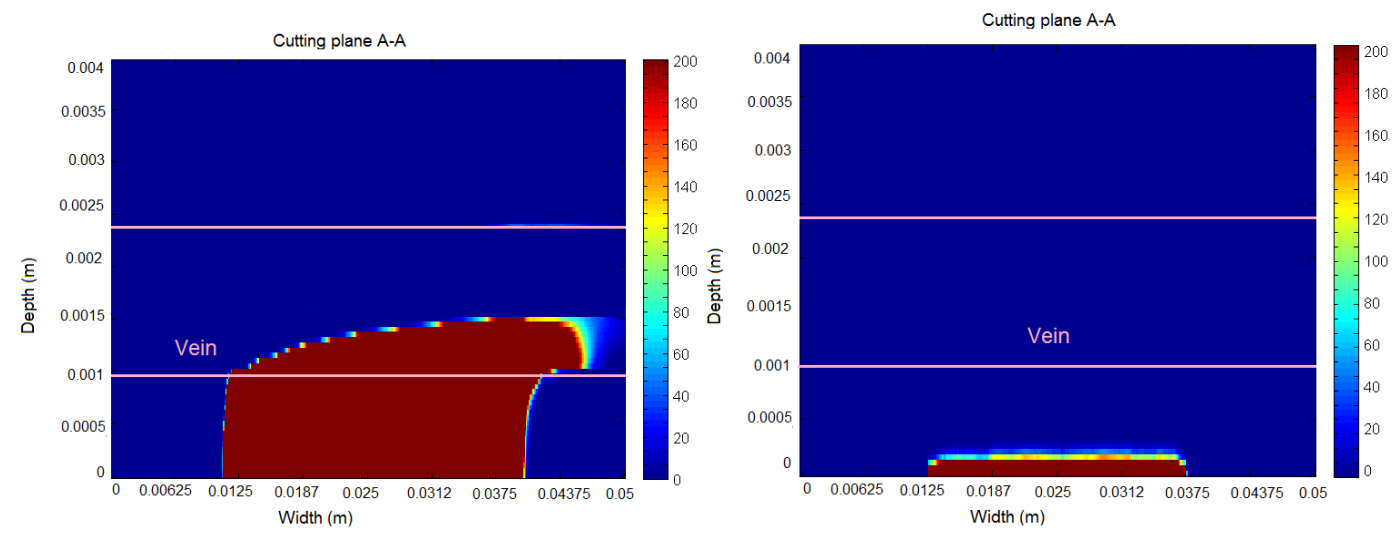

Figure 5: Thermal damage on the longitudinal cutting plane A-A for a burning temperature $T_{\max }=400^{\circ} \mathrm{C}$ during an exposure time $t_{\Omega}=10 \mathrm{~s}$ (left image) and a burning temperature $T_{\max }=100^{\circ} \mathrm{C}$ during an exposure duration $t_{\Omega}=5 \mathrm{~s}$ (right image)

for a severe burn on the transversal cutting plane B-B. The passage of the vein appears very clearly and separates the damage in two lobes. Tissues under the vein are protected.

To study the evolution of thermal damage in the depth of the tissue, we used the check line plotted in the longitudinal cutting plane A-A (see left image of figure 7 ). In the right image of figure 7 are plotted thermal damage versus time for points located on the check line. 

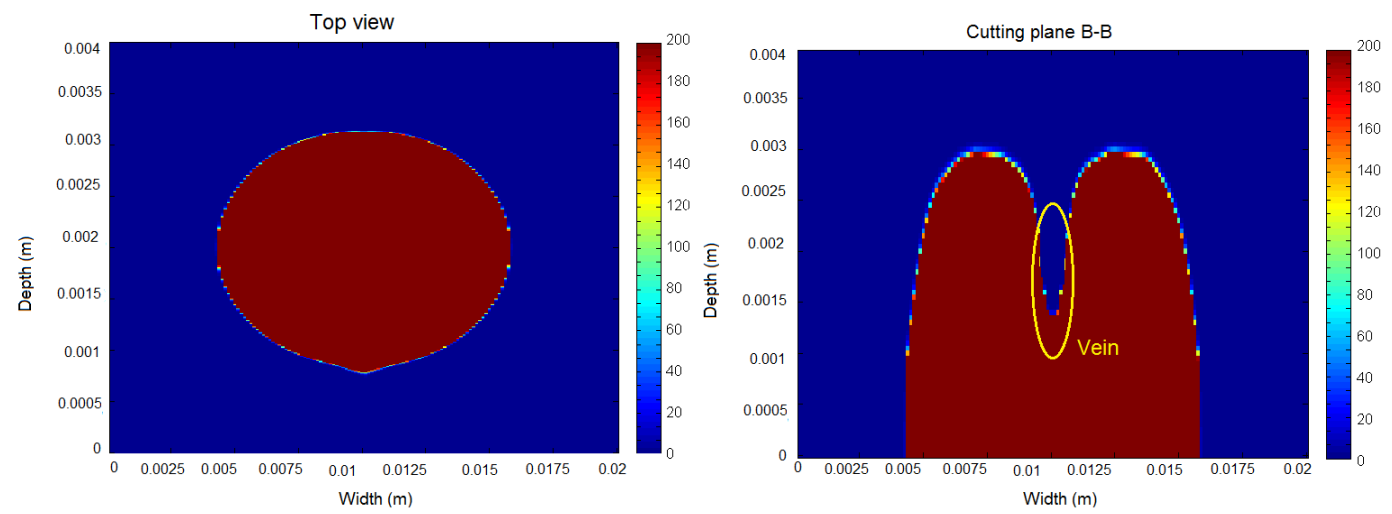

Figure 6: Thermal damage on the upper surface (left image) and on the transversal cutting plane B-B (right image) for a burning temperature $T_{\max }=400^{\circ} \mathrm{C}$ during an exposure duration $t_{\Omega}=10 \mathrm{~s}$
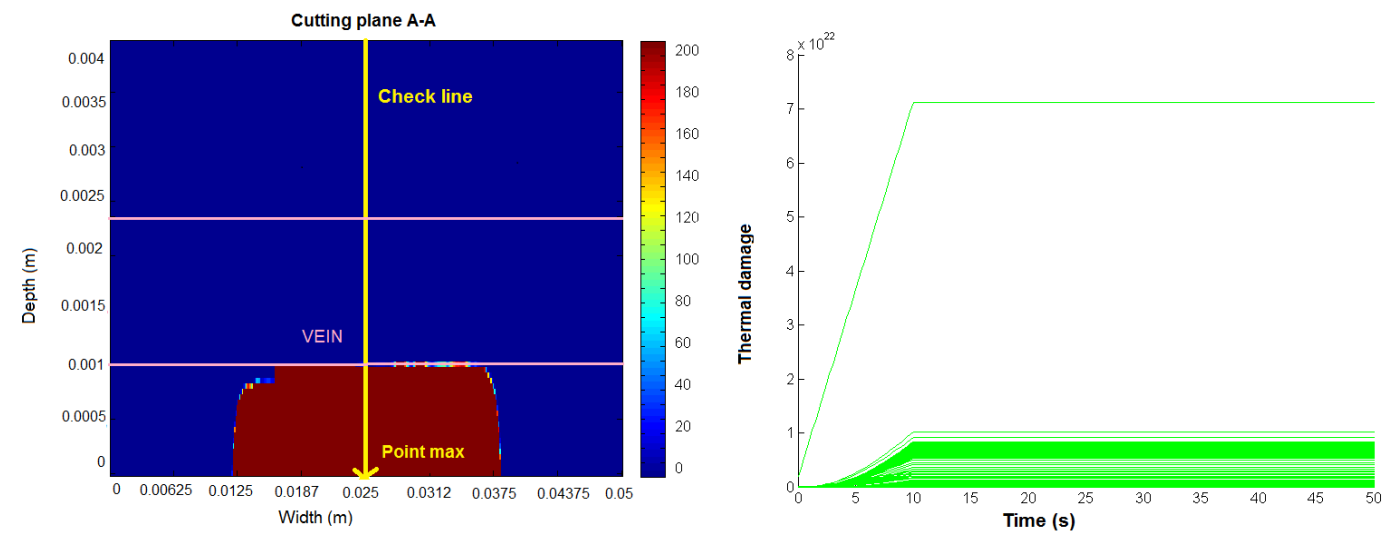

Figure 7: Left image: thermal damage in the longitudinal cutting plane A-A at the end of the simulation and check line; Right image: thermal damage evolution for points located on the check line

The calculations were done with the following values: $A=3.110^{70} \mathrm{~s}^{-1}, t_{\Omega}=10 \mathrm{~s}$ and $T_{\max }=400^{\circ} \mathrm{C}$. Several phenomena are observed:

- The maximum damage is located on the surface in contact with the burner (the upper surface).

- The value of this damage exceeds $10^{4}$, a value which corresponds to the 3rd degree of burn.

- This damage stops brutally and seems not to evolve after 10s. In fact, there is a variation which is not perceptible at this scale $\left(\Omega \simeq 10^{22}\right)$.

- Indeed, a zoom on curves of figure 7 , reported in figure 8 , confirms that the tissue continues to be damaged after the end of the burn $(t \geq 10 \mathrm{~s})$. 


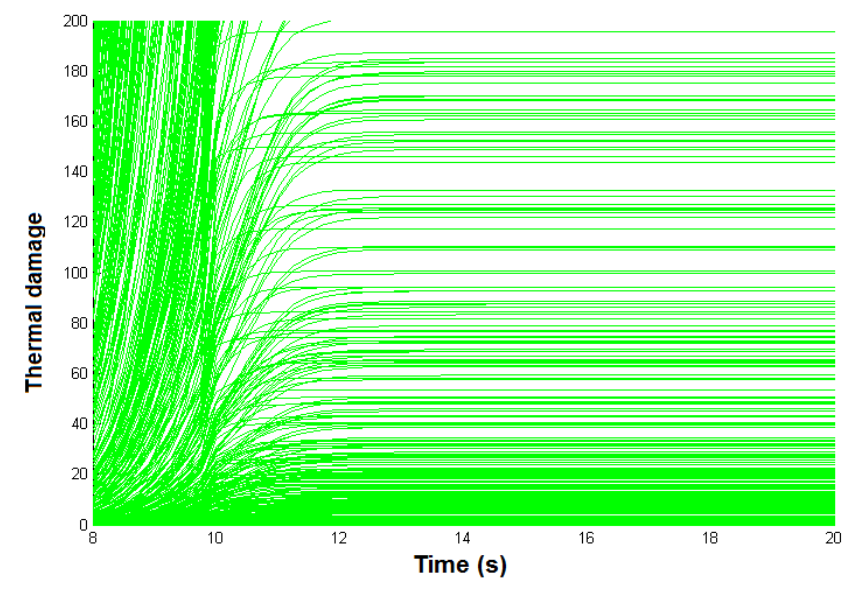

Figure 8: Zoom of figure 7. The tissue continues to be damaged after the end of the burn $t_{\Omega}=10 \mathrm{~s}$

\subsection{Hyperthermia injury evaluation : health care tests}

We now propose to study the value of the thermal damage according to the treatments we suggested previously. The factor of frequency $A$, the imposed temperature $T_{\max }$ as well as the burning exposure duration $t_{\Omega}$ play a significant role to identify the damage generated by a burn. So we not only tried to evaluate the evolution of the damage according to these three parameters, but also to compare them in order to propose the best treatment and to prevent the damage from spreading.

Figure 9 represents the various curves of thermal damage through the skin depth at the end of the treatment. In this numerical test, we used a factor of frequency $A=3.110^{90}$ $\mathrm{s}^{-1}$ during a burning exposure duration $t_{\Omega}=10 \mathrm{~s}$, for various temperatures of burn: $100^{\circ} \mathrm{C}$, $250^{\circ} \mathrm{C}$ and $400^{\circ} \mathrm{C}$.

For a maximal burning temperature $T_{\max }=100^{\circ} \mathrm{C}$, the value of the final depth of damaged tissue was identical for the three treatments. The damaged zone reached $1 \mathrm{~mm}$ of depth. On the other hand, for $T_{\max }=250^{\circ} \mathrm{C}$, the treatment by air remained inappropriate and the treatment by ice seems to be the most effective. Indeed, with this latter alternative, the depth and the intensity of the damage are the smallest. For $T_{\max }=400^{\circ} \mathrm{C}$, the evolution of the damage was almost identical. Depth of damaged tissue reached approximately 3.25 $\mathrm{mm}$. The skin was almost completely injured.

Figure 10 represents the various curves of thermal damage through skin depth during a hyperthermic lapse of time half equivalent to the preceding test, $t_{\Omega}=5 \mathrm{~s}$.

With an exposure duration $t_{\Omega}=5 \mathrm{~s}$ and a very high burning temperature $T_{\max }=400^{\circ} \mathrm{C}$, the damage reached $3 \mathrm{~mm}$ depth. For $T_{\max }=250^{\circ} \mathrm{C}$, the maximum depth of damaged skin was $2.2 \mathrm{~mm}$. For $T_{\max }=100^{\circ} \mathrm{C}$, one observes that the extent of the damage does not depend on the treatments suggested and reached a depth of $0.5 \mathrm{~mm}$. Here again, the treatment by ice seems to be the most suitable.

Figure 11 represents the various curves of thermal damage through skin depth with a factor of frequency $A=3.110^{70} \mathrm{~s}^{-1}$ and a burning exposure time $t_{\Omega}=10 \mathrm{~s}$.

For a burning temperature $T_{\max }=100^{\circ} \mathrm{C}$, the damage was null. For $T_{\max }=250^{\circ} \mathrm{C}$, the 


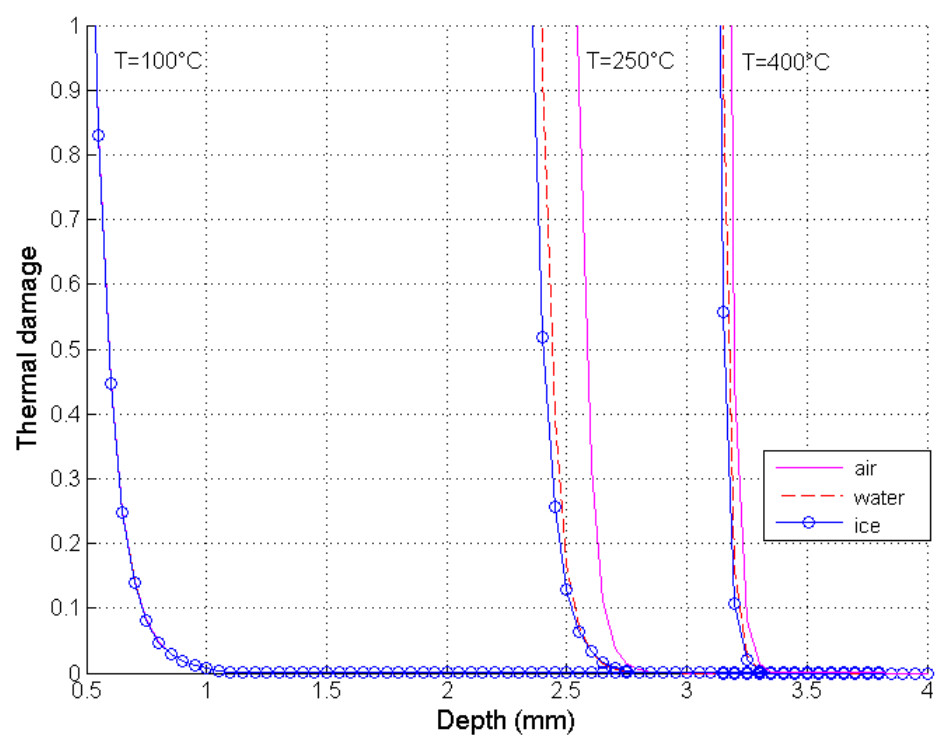

Figure 9: Hyperthermal damage through skin depth $(\mathrm{mm})$ for various temperatures of burn, during an exposure duration $t_{\Omega}=10$ s according to health care treatments (air, water, ice) with a factor of frequency $A=3.110^{90} \mathrm{~s}^{-1}$

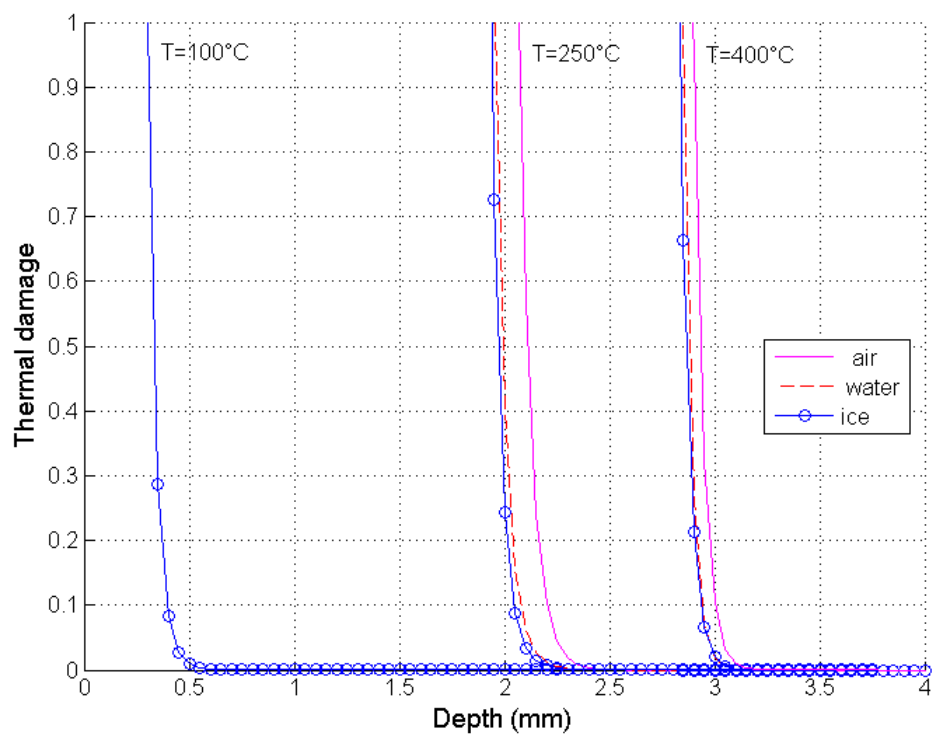

Figure 10: Hyperthermal damage through skin depth $(\mathrm{mm})$ for various temperatures of burn, during an exposure duration $t_{\Omega}=5 \mathrm{~s}$ according to health care treatments (air, water, ice) with a factor of frequency $A=3.110^{90} \mathrm{~s}^{-1}$

damage was identical for the three treatments and reached a depth of $1 \mathrm{~mm}$. Finally, for $T_{\max }=400^{\circ} \mathrm{C}$, the maximum depth of damaged skin was of $1.65 \mathrm{~mm}$. Numerical results show that with this choice of factor of frequency, the health care treatment has no influence 


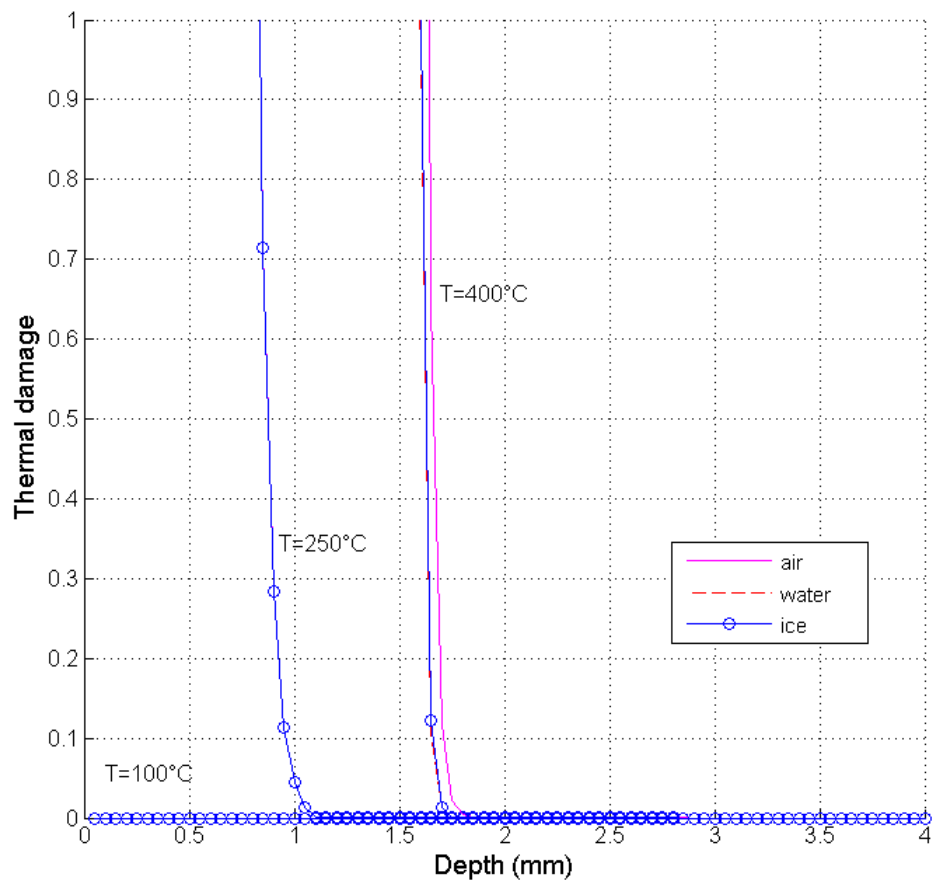

Figure 11: Hyperthermal damage through skin depth $(\mathrm{mm})$ for various temperatures of burn, during an exposure duration $t_{\Omega}=10$ s according to treatments (air, water, ice) with a factor of frequency $A=3.110^{70} \mathrm{~s}^{-1}$

on the depth of damaged skin.

According to the previous results, general comments are the following:

- In the manner of (Becker and Kuznetsov, 2007), we compared the various treatments between them, by changing the conditions of burns (temperature, duration) and the significant parameters of the damage law (activation energy and factor of frequency).

- As reported in (Becker and Kuznetsov, 2005) we showed a transportation of damage along the vein.

- For a high burning temperature $T_{\max }=400^{\circ} \mathrm{C}$, and for all values of the factor of frequency $A$ and burning exposure duration $t_{\Omega}$, the damage was almost identical for the three health care treatments. However, for a short burning exposure duration, the value and the depth of the damaged skin change.

- The burning exposure duration plays a significant role on the extent of the thermal damage on the tissue. For the three results presented above, when burning temperature was not very high $\left(T_{\max }=100^{\circ} \mathrm{C}\right)$, the depth of damaged tissue was identical. The treatments do not affect the extent of the damage.

- Treatments have a significant action only when the burn is fairly important. In this case, the treatment by ice seems to be the most suitable.

- The influence of treatments vanishes when the factor of frequency decrease.

- Contrary to investigations reported in (Kuznetsov, 2006) we did not propose to optimize treatments while varying their parameters (convection coefficient, temperature of water, 
temperature of the ice, duration of the treatment). We placed the study under conditions of classical interventions available on a place of accident and we tried to highlight the best treatment between two possible.

- We also showed that the reaction time is even more determining than the treatment for this damage model. Beyond 5 seconds of reaction, it is too late to limit the damage, whatever the applied treatment.

These results are partial. To confirm the tendencies, it would also be necessary to test the influence of the coefficient of transfer $h_{\text {water }}$, the temperature of water, the temperature of the ice, the transfer of heat between the ice and the skin, the duration of the reaction time and the duration of the treatment.

\section{Conclusion}

We developed a numerical model of thermal damage coupled with a 3D multi-layer model including blood perfusion and a vein. A light transport of the damage can be observable. Such a transport is caused by the vein. The passage of the vein appears very clearly. It separates the damaged zone into two lobes and protects tissues that are located under it. In addition, this model of damage allows us to suggest two treatments for the burns, while trying to decrease the spread of the damage. The factor of frequency, the burning temperature, as well as the burning exposure duration play a significant role in identifying the severity of the damage. Calculations showed that the spread of the damage could be decreased. In our examples, it appears that a treatment simulating ice apposition on the burn is more effective than a treatment by flow of water. Our results show that this report is true only under conditions of moderate burn. We also showed that the reaction time is even more determining than the treatment for this damage model. Beyond 5 seconds of reaction, it is too late to limit the damage, whatever the applied treatment. This model opens up new perspectives for future work on an improvement of the treatments of burns.

\section{References}

Becker SM, Kuznetsov AV. 2005. Numerical Modeling of In Vivo Plate Electroporation Thermal Dose Assessment. Journal of Biomechanical Engineering 128(1):76-84.

Becker S, Kuznetsov A. 2007. Thermal damage reduction associated with in vivo skin electroporation: A numerical investigation justifying aggressive pre-cooling. International Journal of Heat and Mass Transfer 50:105 - 116.

- 2007. Numerical assessment of thermal response associated with in vivo skin electroporation: the importance of the composite skin model. Journal of biomechanical engineering 129:330-340.

Chang IA, Nguyen UD. 2004. Thermal modeling of lesion growth with radiofrequency ablation devices. BioMedical Engineering OnLine 3(27):713 - 717. 
Diller KR, Hayes LJ. 1983. ASME; A Finite Element Model of Burn Injury in Blood-Perfused Skin. Journal of Biomechanical Engineering 105(3):300-307.

Fuentes D, Cardan R, Stafford RJ, Yung J, III GDD, Feng Y. 2010. High-fidelity Computer Models for Prospective Treatment Planning of Radiofrequency Ablation with In Vitro Experimental Correlation. Journal of Vascular and Interventional Radiology 21(11):1725 -1732 .

Gowrishankar T, Stewart D, Martin G, Weaver J. 2004. Transport lattice models of heat transport in skin with spatially heterogeneous, temperature-dependent perfusion. BioMedical Engineering OnLine 3:3-42.

Jiang S, Ma N, Li H, Zhang X. 2002. Effects of thermal properties and geometrical dimensions on skin burn injuries. Burns 28(8):713 - 717 .

Klinger H. 1974. Heat transfer in perfused biological tissue. I. general theory. Bull. Math. Biol. 21:494-497.

Kuznetsov A. 2006. Optimization problems for bioheat equation. International Communications in Heat and Mass Transfer 33(5):537 - 543.

Moritz AR, Henriques FC. 1947a. Studies in thermal injury I. The Conduction of Heat to and through Skin and the Temperatures Attained Therein. A Theoretical and an Experimental Investigation. Am J Pathol 23:531-549.

. 1947b. Studies in thermal injury II. The relative importance of time and surface temperature in causation of cutaneous burns. Am J Pathol 23:695-720.

Museux N, Perez L, Autrique L, Agay D. 2012. Skin burns after laser exposure: Histological analysis and predictive simulation. Burns 38(5):658 - 667 .

$\mathrm{Ng}$ E, Chua L. 2002. Comparison of one- and two-dimensional programmes for predicting the state of skin burns. Burns 28(1):27 - 34 .

Pennes HH. 1948. Analysis of Tissue and Arterial Blood Temperatures in Resting Human Forearm. Journal of Applied Physiology 1:93-122.

Ratovoson D, Huon V, Costalat V, Jourdan F. 2011. Combined model of human skin Heat transfer in the vein and tissue: experimental and numerical study. Quantitative InfraRed Thermography Journal 8(2):165-186.

Roetzel W, Xuan Y. 1998. Transient response of the human limb to an external stimulusTransient response of the human limb to an external stimulus. Int. J. Heat Mass Transfer 41:229-239.

Sramek C, Paulus YM, Nomoto H, Huie P, Palanker D. 2009. Finite element model of thermal processes in retinal photocoagulationIn: Society of Photo-Optical Instrumentation Engineers (SPIE) Conference Series. Feb. (. Society of Photo-Optical Instrumentation Engineers (SPIE) Conference Series; vol. 7175). 
Stoll A, Greene L. 1959. Relationship between pain and tissue damage due to thermal radiation. Journal of applied physiology 14(3):373-382.

Weinbaum S, Jiji L. 1985. A new simplified bioheat equation for the effect of blood flow on local average tissue temperature. ASME Trans. J. Biomech. Eng. 107:131-141.

Weinbaum S, Jiji L, Lemos D. 1984. Theory and Experiment for the Effect of Vascular Temperature on Surface Tissue Heat Transfer - Part I: Anatomical Foundation and Model Conceptualization. ASME Journal of Biomedical Engineering 106:321-330.

Wright NT. 2003. On a relationship between the Arrhenius parameters from thermal damage studies.. Journal of biomechanical engineering 125(2):300-304.

Xu F, Lu T, Seffen KA. 2008. Biothermomechanics of skin tissue. Journal of the Mechanics and Physics of Solids 56 (5):1852-1884. 